\title{
The combined use of senometry and ultrasonography for breast cancer surgical planning
}

\author{
Ștefan Voiculescu ${ }^{1,2}$, Răzvan V. Scăunașu ${ }^{1,2}$, Matei Moroșanu², Andreea Greșanu ${ }^{2}$, \\ Bogdan Popescu ${ }^{1}$, Traean Burcos ${ }^{1,2}$ \\ ${ }^{1}$ Carol Davila University, Department of General Surgery, Bucharest, Romania \\ ${ }^{2}$ Colțea Clinical Hospital, Department of General Surgery, Bucharest, Romania
}

\begin{abstract}
Objective
Ultrasound exerts an important role in breast cancer diagnosis protocol, but the use of eco-senometry can also improve therapeutic options, surgical planning and technique.

Methods

We describe various measurement formulas and techniques that are applied in order to acquire important information regarding the breast and its lesions.

Results

Senometry and ultrasonography have been proven to be very effective, reaching up to reliability levels as high as 0.997 and accuracy levels as high as $99.6 \%$.

Conclusions

Senometry and ultrasonography have clearly demonstrated their value in breast cancer diagnosis and treatment. These methods are reliable, inexpensive and can be easily performed by the surgeon. More advances in the domain are expected in the future.
\end{abstract}

Keywords: senometry, ultrasonography, breast cancer, surgical planning 


\section{Introduction}

Breast cancer is an important health problem worldwide and most of the patients require surgical treatment for their disease. The surgical management of breast neoplasia underwent significant evolution in the last century as a result of early diagnosis and due to better understanding of the disease biology. Van Maaren et al showed in a population-based study that the 10 years survival rate was better in patients who underwent breast conserving surgery plus radiotherapy than in those who underwent mastectomy. The study only included patients with early-stage breast cancer (1).

Conservative surgery is more and more used in treating these patients. However, many of the patients treated with conservative breast surgery have poor cosmetic outcome (because of the patient's age, tumour location, tumour size etc.). In many of these cases, patients usually need further radiotherapy, reexcisions, leading thus to several complications.

In order to obtain a good cosmetic outcome, the excised volume needs to be as small as possible. The calculated resection rate (total resected volume/optimal resected volume) is in this case very important. However, a ratio of over 4 is still associated with positive margins in $11 \%$ of cases (2).

The importance of the resection margins has been made clear by the Joint SSO - ASTRO Consensus, which shows that positive margins double the risk of local recurrences, regardless of radiation boosts, systemic treatment or favorable biology. Failure in obtaining acceptable margins can lead not only to an increased risk of local recurrences, but also to further re-excisions and poor cosmetic outcome, causing the patient anxiety and discomfort (3).

The use of eco-senometry can help in resecting a smaller volume of the breast tissue, maintaining negative tumor margins at the same time.
Also, the use of intraoperative ultrasonography is a valuable method that can lower the number of excised tumors with positive margins (4).

\section{Discussion}

\section{Eco-senometry methods}

Senometry can be used in order to evaluate the breast and its lesions, thus bringing forth a more detailed and accurate preoperative description. By using different measuring devices (and/ or formulas) such as the Astra Zeneca senometer, the Grossman Rounder Device, different software techniques or just a simple ruler, it can provide precise measurements.

The purposes of senometry are to obtain the exact location of a tumour, its dimensions, to evaluate the breast volume, to evaluate the necessary resection volume, to plan the operation, to evaluate the lesion during the operation and to evaluate the outcome.

Ultrasound guided senometry (eco-senomerty) is a valuable method that can be used in order to achieve the above-mentioned goals. Renzo Brun del Re described this technique regarding non-palpable breast tumours. Using the probe of an ultrasonograph, the breast will be scanned in order to find the lesion (5). The ultrasonic lesion should then lie exactly in the centre of the image (Figure 1).

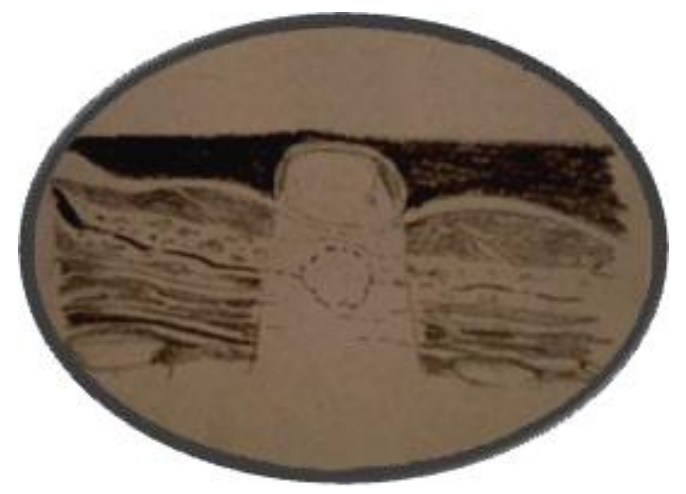

Figure 1. The ultrasonic lesion

The probe will be lifted slightly, in order to place a finger or a coin just beneath the probe (Figure 2). The coin/finger now lies directly above the lesion and can be used to mark the position on the adjacent skin (Figure 3) (5). The lesion is then measured using the 
senometer. The distance from the nipple to the lesion and the angle of the lesion (in the form of clock time) are noted (5).

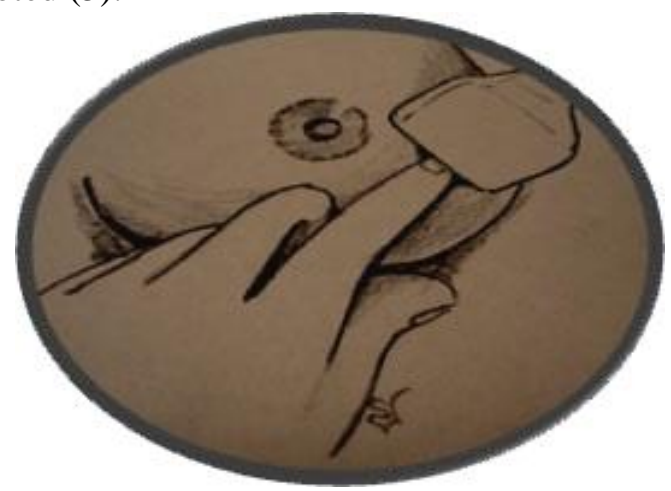

Figure 2. Placing a finger just beneath the probe

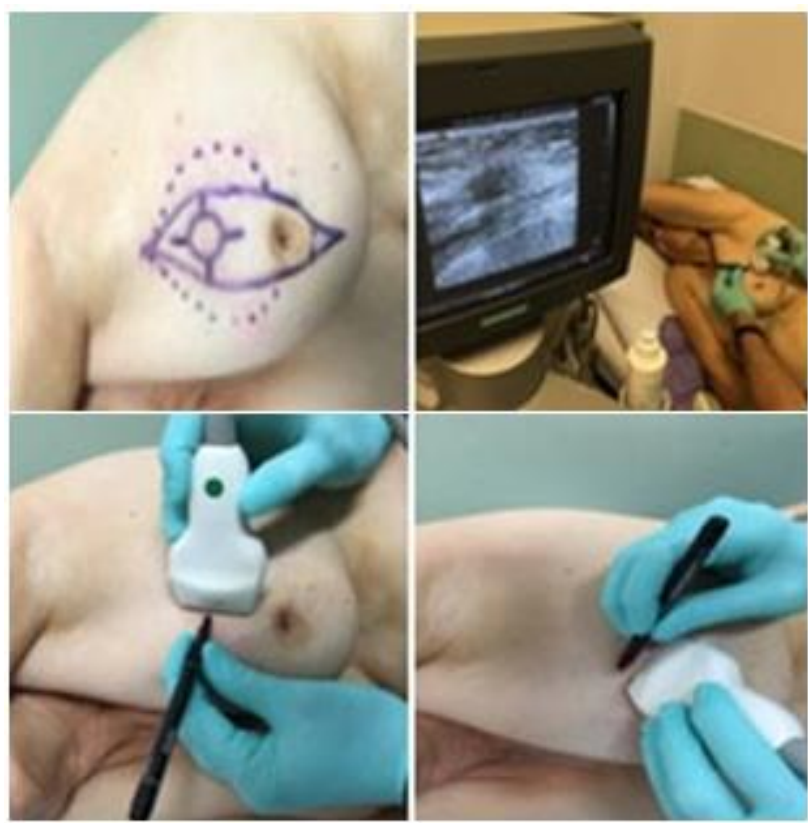

Figure 3. Measuring the lesion

The eco-senometric evaluation allows for the following characteristics of the lesion to be described (Figures 4, 5):

- location (left/right breast; quadrant)

- distance from the nipple

- angle (in form of clock time)

- depth

- volume (measured using documentation in 3 planes)

- mobility

- margin aspects

If surgery is indicated (as a result of the histopathological report), breast volume and resection volume must be taken into account, in order to obtain a good cosmetic outcome.

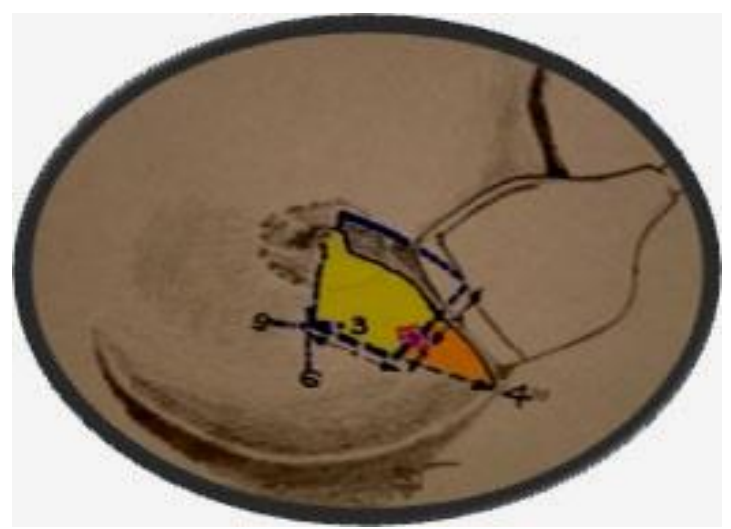

Figure 4. Characteristics of the lesion

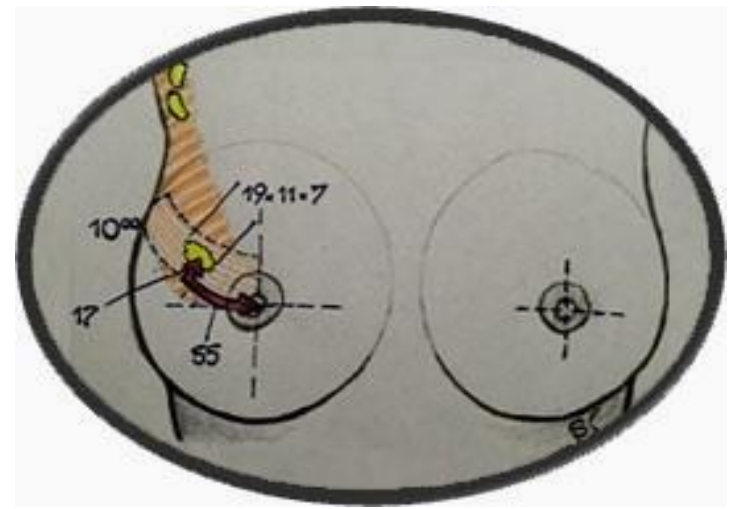

Figure 5. Characteristics of the lesion

Preoperative breast volume measurement techniques (that use different materials and are based on certain principles) are applied. The Grossman Rounder is a cone-shaped graduated device that covers the breast in order to determine its volume $(6,7)$. The anatomic (anthropometric) method uses a specific formula based on anatomical projections. A different formula is used when calculating breast volume based on a mammography (7). The casting technique consists in creating an empty shape of the breast by making a cast around it. The cast is then filled with water or sand in order to determine breast volume $(8,9)$. Archimedes' principle uses the amount of water displaced by the breast in order to calculate its volume (7). Other methods such as sonography, magnetic resonance imaging (MRI) and different 3D scanning techniques can also be used to determine breast volume (10).

Authors frequently describe the ideal resection volume as being a sphere (the tumour), surrounded by an additional $1 \mathrm{~cm}$ of (supposedly) normal breast tissue (11). The following formula can be used in order 
to calculate the exact volume: $V=\pi / 3 x \quad(r+m) 3, r$ meaning the radius of the lesion and meaning the desired margin. A cylindrical excision (Figure 6) is also a good and preferred option: $\mathrm{V}=\pi(\mathrm{r}+\mathrm{m}) 2 \times \mathrm{h}$ (h meaning the distance from the skin to the muscle). The actual performed resections are, although, ellipsoid. By dividing the ellipsoid (actual) resection volume to the spherical/cylindrical (optimal) resection volume, the calculated resection ratio is obtained. This parameter is very important: too high and the cosmetic outcome is compromised, too low and the risk of positive tumor margins increases.

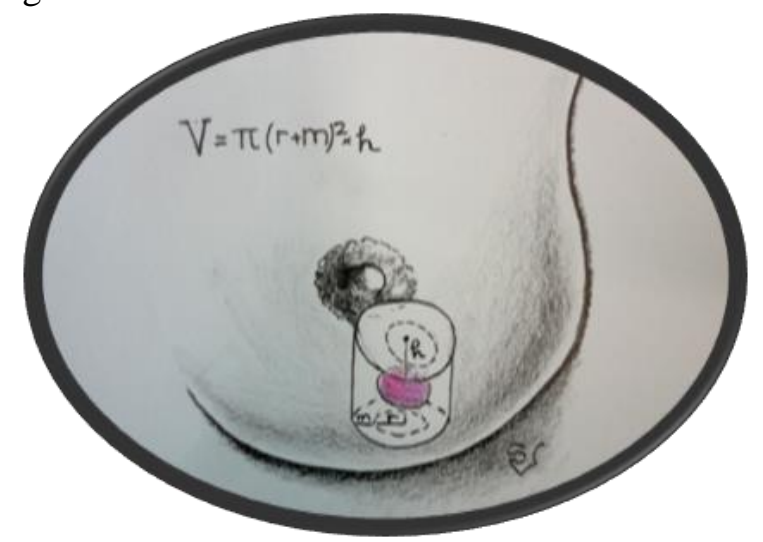

Figure 6. The cylindrical excision

The volume of the removed tissue can be measured applying Archimedes' principle of water displacement, Figure 7 (7). Authors frequently use this technique also as a reference point in order to determine the accuracy of different breast volume measuring methods, by comparing the preoperative determined breast volume with the intraoperative determined volume of the mastectomy specimen $(7$, $12,13)$.

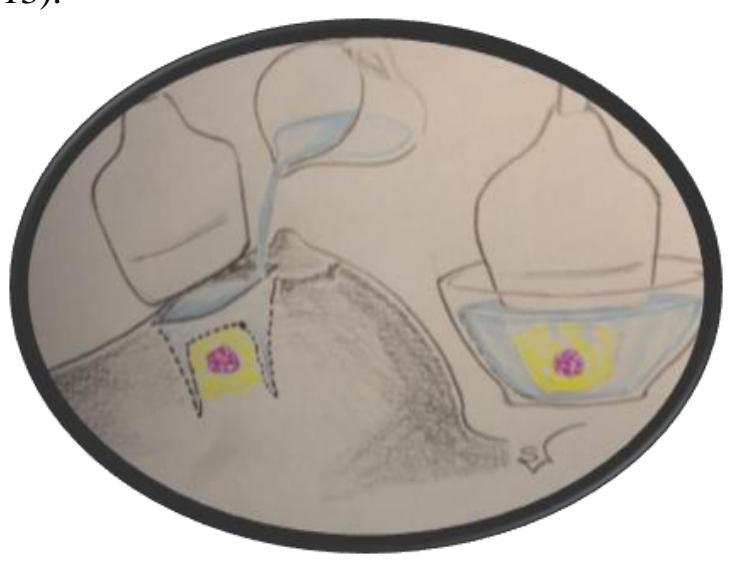

Figure 7. The volume of the removed tissue

\section{Performance overview}

In order to take out the entire tumor and leave as much normal breast tissue at its place as possible, the accuracy of the performed measurements is vital. The intraoperative evaluation of the lesion is also important.

Kayar et al showed the importance of preoperative breast volume measuring techniques in a study performed on 30 patients, in which reliability levels vary from 0.934 (Grossman Rounder Device) to 0.997 (mammography) (7). The costs of different methods vary from almost zero (the Grossman Rounder Device, the anthropometric method and the water displacement principle), to extremely expensive, an MRI scan costing 1400 USD (7). This proves the need of determining the cost effectiveness of a technique, before applying it. The Grossman Rounder Device seems thus not only to be very cost-effective, but very convenient as well $(7,14)$.

Butler-Henderson $\mathrm{K}$ et al demonstrated in their systematic review that intraoperative ultrasound margin assessment technique can reach up to sensitivity levels as high as $100 \%$ (15). Edward St. John et al also revealed high sensitivity and specificity values for this method in their meta-analysis (16).

The use of senometry in medical practice has been demonstrated to improve the diagnostic and therapeutic techniques used in breast tumours. Many senometric methods are very reliable, inexpensive and can be easily performed by the surgeon. While other lesion localization techniques (such as hook/wire localization, methylene blue dye mapping, etc.) are difficult, require more medical staff and can lead to complications, the eco-senometry is a non-invasive procedure that can be performed by the surgeon alone. However, for a more exact localization of the tumor, the senometric markings and measurements can be used in order to guide the above-mentioned procedures. Combined with the intraoperative ultrasound margin assessment technique, senometry can provide a satisfactory outcome. 
Eco-senometry is a fairly new approach regarding breast tumors. In the future, we expect that more advances will be made in this domain and that ecosenometry will become a part of the routine examination in breast lesions. The use of software assisted senometric techniques can and probably will improve the accuracy of the measurements even more (Figures 8, 9).

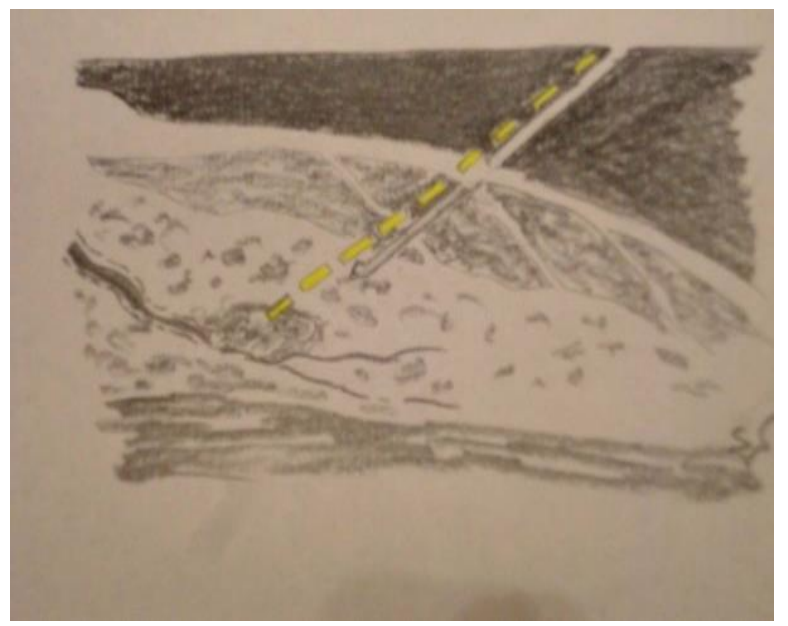

Figure 8. Software assisted senometric technique

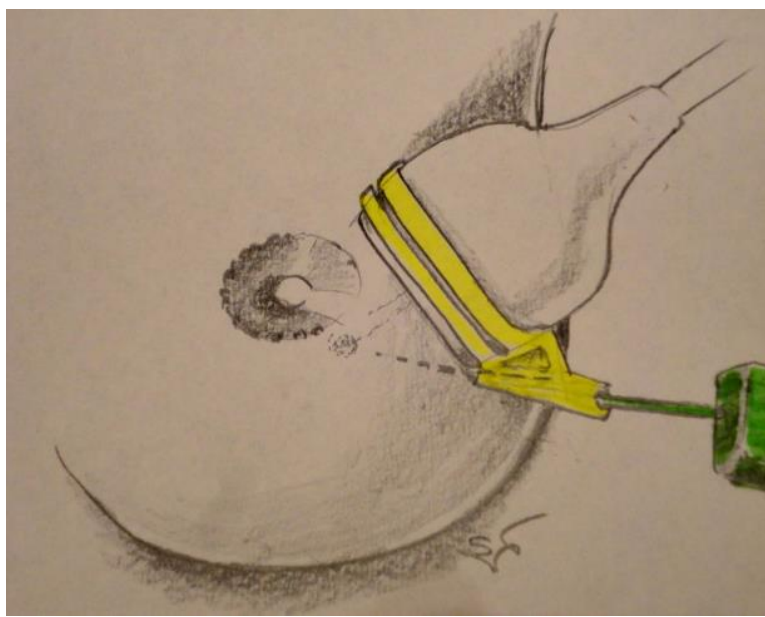

Figure 9. Software assisted senometric technique

\section{Conclusions}

The combined use of senometry and ultrasonography has been proved to increase the accuracy of tumour diagnosis and excision, thus meaning that senometry can be used by every physician in addition to other diagnostic or therapeutic procedures in order for the medical goals to be achieved.

Senometry and ultrasonography have clearly demonstrated their value in breast cancer diagnosis and treatment. Combining the two and using the ecosenometric technique should provide similar results. However, more studies need to be performed regarding this issue in order to draw such a conclusion.

\section{References}

1. van Maaren MC, de Munck L, de Bock GH, Jobsen JJ, van Dalen T, Linn SC, Poortmans P, Strobbe LJA, Siesling S. 10 year survival after breast-conserving surgery plus radiotherapy compared with mastectomy in early breast cancer in the Netherlands: a population-based study. Lancet Oncol. 2016; 17(8): 1158-70. PMID: 27344114, https://doi.org/10.1016/S14702045(16)30067-5

2. Krekel N, Zonderhuis B, Muller S, Bril H, van Slooten HJ, de Lange de Klerk E, van den Tol P, Meijer S. Excessive Resections in BreastConserving Surgery: A Retrospective Multicentre Study. Breast J. 2011; 17(6): 602-9. PMID: 22050281 ,

https://doi.org/10.1111/j.1524-4741.2011.01198.x

3. Moran MS, Schnitt SJ, Giuliano AE, Harris JR, Khan SA, Horton J, Klimberg S, ChavezMacGregor M, Freedman G, Houssami N, Johnson PL, Morrow M; Society of Surgical Oncology; American Society for Radiation Oncology. Society of Surgical Oncology-American Society for Radiation Oncology consensus guideline on margins for breast-conserving surgery with wholebreast irradiation in stages I and II invasive breast cancer. J Clin Oncol. 2014; 32(14): 1507-15. PMID: 24516019,

\section{https://doi.org/10.1200/JCO.2013.53.3935}

4. Bunting PW, Cyr AE, Margenthaler JA. Randomized trial evaluating intraoperative ultrasound guidance for palpable breast cancer excision. Expert Rev Med Devices. 2013; 10(3): $\quad 317-20 . \quad$ PMID: 23668704 , https://doi.org/10.1586/erd.13.11 
5. Renzo Brun del Re. Minimally Invasive Breast Biopsies. Documentation and Correlation of Senologic Findings. Springer Science \& Business Media 2009; pp. 19. ISBN 978-3-540-31611-4

6. Grossman A, Roudner LA. A simple means for accurate breast volume determination. Plast Reconstr Surg. 1980; 66(6): 851-2. PMID: 7443851, $\quad$ https://doi.org/10.1097/00006534198012000-00009

7. Kayar R, Civelek S, Cobanoglu M, Gungor O, Catal H, Emiroglu M. Five Methods of Breast Volume Measurement: A Comparative Study of Measurements of Specimen Volume in 30 Mastectomy Cases. Breast Cancer (Auckl). 2011; 5: 43-52. PMID: 21494401,

https://doi.org/10.4137/BCBCR.S6128

8. Edsander-Nord A, Wickman M, Jurell G. Measurement of breast volume with thermoplastic casts. Scand J Plast Reconstr Surg Hand Surg. 1996; 30(2): 129-32. PMID: 8815982, https://doi.org/10.3109/02844319609056394

9. Campaigne BN, Katch VL, Freedson P, Sady S, Katch FI. Measurement of breast volume in females: description of a reliable method. Ann Hum Biol. 1979; 6(4): 363-7. PMID: 533239, https://doi.org/10.1080/03014467900003741

10. Hoeffelin H, Jacquemin D, Defaweux V, Nizet JL. A Methodological Evaluation of Volumetric Measurement Techniques including ThreeDimensional Imaging in Breast Surgery. Biomed Res Int. 2014; 2014: 573249. PMID: 24511536, PMCID: PMC3910661

https://doi.org/10.1155/2014/573249

11. Krekel NM, Zonderhuis BM, Stockmann HB, Schreurs WH, van der Veen H, de Lange de Klerk ES, Meijer S, van den Tol MP. A comparison of three methods for nonpalpable breast cancer excision. Eur J Surg Oncol. 2011; 37(2): $\quad$ 109-15. $\quad$ PMID: 21194880 , https://doi.org/10.1016/j.ejso.2010.12.006

12. Losken A, Seify H, Denson DD, Paredes AA Jr, Carlson GW. Validating three-dimensional imaging of the breast. Ann Plast Surg. 2005; 54(5): 471-6. PMID: 15838205, https://doi.org/10.1097/01.sap.0000155278.87790. $\underline{\mathrm{a} 1}$

13. Yip JM, Mouratova N, Jeffery RM, Veitch DE, Woodman RJ, Dean NR. Accurate assessment of breast volume: a study comparing the volumetric gold standard (direct water displacement measurement of mastectomy specimen) with a 3D laser scanning technique. Ann Plast Surg. 2012; 68(2): 135-41. PMID: 21587046, https://doi.org/10.1097/SAP.0b013e31820ebdd0

14. Caruso MK, Guillot TS, Nguyen T, Greenway FL. The cost effectiveness of three different measures of breast volume. Aesthetic Plast Surg. 2006; 30(1): 16-20. PMID: 16411159, https://doi.org/10.1007/s00266-004-0105-6

15. Butler-Henderson K, Lee AH, Price RI, Waring K. Intraoperative assessment of margins in breast conserving therapy: a systematic review. Breast. 2014; 23(2): 112-9. PMID: 24468464 , https://doi.org/10.1016/j.breast.2014.01.002

16. St John ER, Al-Khudairi R, Ashrafian H, Athanasiou T, Takats Z, Hadjiminas DJ, Darzi A, Leff DR. Diagnostic Accuracy of Intraoperative Techniques for Margin Assessment in Breast Cancer Surgery: A Meta-analysis. Ann Surg. 2017; 265(2): 300-10. PMID: 27429028, https://doi.org/10.1097/SLA.0000000000001897 